operation, and on opening the body the ureters were found considerably dilated; the right kidney was inflamed, and the left one contained a quantity of pus; with the exception of these four patients, all the rest were cured in an average period of one month.

At the Hopital of Santa Maria di Loretto five patients operated on by $\mathrm{M}$. Petrunti all recovered, two in fourteen days, and two more in less than twenty.

If we take a statistical view of all the operations for stone performed in the hospitals of Naples for the last fourteen years, we find that from 1821 to the autumn of 1834, there were operated on as follows :-

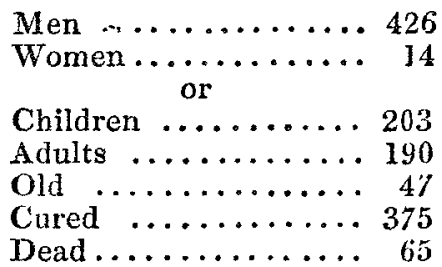

Hence the number of males affected is to that of the females as $8 \frac{5}{7}$ to 1 nearly; the number of children, comprising those below fifteen years, almost equals the num.. ber of adults and old people together, and the mortality is as 5.769230 to 1 .

\section{IMPERFORATE VAGINA.}

\section{To the Editor of The LAnceT.}

Sin,-The publication of the following case in the pages of your valuable journal will tend, I trust, to illustrate the necessity on the part of obstetric practitioners, of carefully examining the female infant immediately after birth, to prevent any malformation of the genital organs at that time from passing unnoticed, and from which the most distressing consequences, both moral and constitutional, must eventually succeed. I remain, Sir, your constant reader,

J. M. TATLOCK,

Surgeon to the Castlebrilge Dispensary.

Wexford, April 2, 1835.

About a fortnight since I was requested to see the daughter of a respectable farmer residing in the neighbourhood of Wex-

No. 606 . ford, who, I was informed, was seriously ill, and required imnediate assistance. On my arrival $I$ found the parient sufiering much from urinary fever, the bladder greatly distended, she having had complete retention of urine for two days previous. She stated that she was twenty-one years of age, had nerrer had any menstrual dis. charge, and enjoyed good health until within the last five or six months, during which time she had constant pain in the right side, loss of appetite, and tenderness upon pressure over the whole abdomen; she also experienced great difficulty in expelling the contents of the bladder, which was darker than natural, and occasionally mixed with a bloody mucus. I immediately proceeded to the introduction of the catheter, and drew off a large quantity of dark fetid urine, and on applying my hand over the region of the uterus, I discovered that it was considerably enlarged, of an oblong figure, and extending above the umbilicus, differing mach in shape and situation from the gravid uterus during the first months of gestation. On further examination $\mathrm{I}$ found an imperforate vagina, which $I$ pronounced to be the cause of all her distressing symptoms, and proposed an operation as the only means of relief, which was readily agreed to.

Having prescribed an active aperient, with warm fomentations, and an anodyne enema, assisted by my friend, surgeon Nunn, I proceeded as follows:-The patient being placed on a table, as in the operation for lithotomy, I introduced a staff into the bladder, and commenced my incision about half an inch below the orifice of the urethra, continuing it an inch downwards and backwards towards the anus. Cutting through a hard fleshy substance of at least an inch and a quarter thick, which plugged up the orifice of the vagina, and on dividing it gave exit to upwards of two quarts of dark viscous blood, resembling treacle, without being in the least putrid, or having a disagreeable odour, and which, from its pressure on the neck of the bladder, had caused the retention of urine. One remarkable circumstance connected with the discharge of the fluid, was the violent uterine action, which continued during its expulsion, similar to, and apparently as distressing as, the pains of labour.

I concluded by introducing a plug, smeared with oil, into the wound, which plug I have advised to be worn occasionally, and I an happy to say that my patient has now perfectly recovered, and is attend. ing to her ordinary duties. 